\title{
Covid-19 y biopoder: cómo resistir la normalización de una crisis
}

\section{Covid-19 and biopower: How to resist the normalization of crisis}

\author{
John Camilo García Uribe*
}

https://doi.org/10.36105/mye.2021v32n1.02

\section{Resumen}

Es un análisis y reflexión sobre la normalización de la crisis como un ejercicio del biopoder, sus posibles consecuencias y formas de resistencia. Todo ello, en el marco contextual de la pandemia por el virus SARS-Cov-2, se toman como principales referentes conceptuales a Michel Foucault, Hans Jonas y Jared Diamond. Se hace una lectura de la teoría foucaultiana del poder para abordar la relación entre normalización de la crisis y el biopoder. Las propuestas de Diamond y Jonas se ponen en un marco dialógico interpretativo, a través del cual se pretende dar un enfoque crítico responsivo ante la situación actual, desde una postura que toma el miedo, no como un factor paralizador y aturdidor, sino como un agente movilizador que obliga a pensar, reflexionar $y$, con ello, a poder responder, ampliar los círculos de compasión y empatía para cuidar de la vida en una casa común y resistir ante la normalización del biopoder.

Palabras clave: normalización, crisis, biopoder, coronavirus, compasión.

\footnotetext{
* Enfermero Profesional de la Universidad de Antioquia, maestrando en Bioética en la Universidad CES, Fundación Clínica del Norte, Colombia. Correo electrónico: johnc.garcia@udea.edu.co https://orcid.org/0000-0002-3810-5583

Recepción: 20 de septiembre de 2020. Aceptación: 15 de octubre de 2020.
}

Medicina y Ética - Enero-Marzo 2021 - Vol. 32 - Núm. 1 


\section{Introducción}

La pandemia causada por el virus SARS-Cov-2 -también llamado coronavirus o Covid-19-, aunque no es la primera en la historia de la humanidad, sí es la primera del siglo XXI, puesto que ni el SARS Cov, Mers Cov (1), ni el Ébola llegaron al alcance de pandemia. No obstante, en la actualidad aún se arrastra la carga de otras pandemias del siglo pasado, como la del VIH y la tuberculosis, ambas con una tasa de mortalidad ostensiblemente mayor, pero que tienen unas connotaciones biológicas y socioculturales diferentes, dado que generan exclusión y estigmatización al que padece la enfermedad, lo que se traduce en una concepción un tanto ajeno-lejana de la enfermedad, por lo que su impacto en la sociedad actual es, por ende, diferente. El coronavirus, por su parte, se ha expandido exponencial y globalmente. Pareciera no distinguir por raza, género, clase, profesión, hábitos de vida, entre otros factores. El mero hecho de respirar o entrar en contacto con superficies contaminadas con el virus parece ser el factor detonante para una posible infección. Pero no se pueden dejar de lado otros factores como el acceso a agua potable, desinfectantes, comida, empleo y salud, que pueden ser incluso más letales que el mismo virus, y algunos de ellos han sido y siguen siendo clasificados como ingredientes de una nueva normalidad.

El mundo hiperconectado -en el que la cadena de producción y consumo está hiperfragmentada, y en el que antes de la pandemia se registraban alrededor de 120 mil vuelos comerciales por día (2)-, supone un escenario ideal para la transmisión de un microorganismo nuevo y desconocido, en el que muchos de los infectados no presentan síntomas, pero son hospederos en los que el virus se reproduce y desde los que se transmite. Esta misma conectividad ha facilitado el flujo de información a través de los medios de comunicación y redes sociales. En efecto, se puede tener información de primera mano y, casi de inmediato, del número de contagios por día, de la tasa de mortalidad, medidas de contención y, en general,

Medicina y Ética - Enero-Marzo 2021 - Vol. 32 - Núm. 1 
de cómo transcurre «la nueva normalidad en China y Europa», si es que puede llamarse normal; igualmente, del cambio radical de los hábitos y costumbres de la sociedad, que van desde evitar el contacto estrecho con otras personas, el uso de mascarillas, el aumento de medidas de higiene, hasta llegar a coartar la libertad y la autonomía de los individuos bajo el confinamiento. A raíz de ello han surgido muchos interrogantes y resurgen otros tantos, ante una crisis que trae al plano de lo tangible otras crisis que parecían subyacer en el olvido de la invisibilización. ¿Por qué se cedió tan fácilmente a un cambio de los hábitos de vida? Replicando a un cuestionamiento de Agamben (3), ¿es acaso el virus un pretexto para coartar las libertades de los seres humanos, a través de mecanismos de estado de excepción? ¿El estado de excepción se impondrá como la solución idónea ante la crisis? ¿El confinamiento y el aislamiento social recrudecerán fenómenos como la exclusión social, la aporofobia (rechazo y aversión a los pobres), la xenofobia y el racismo? ¿Es una utopía pensar en la empatía, la compasión y la solidaridad en tiempos de crisis?

\section{Resultados}

\section{La normalización de una «nueva normalidad», un ejercicio del biopoder}

Usualmente, nos referimos al poder como un algo, una cosa ajena, externa, algo plenamente identificable; incluso desde la misma nominación y representación de «el poder» como sustantivo y no como verbo; se pasa de largo, y el mismo poder inmerso en el lenguaje termina dominando un discurso, que precisamente reproduce el mecanismo del poder. «El poder no constituye una propiedad de los seres, sino la esencia misma de todo cuanto es; es decir, de todo cuanto vive. El ser no es otra cosa que voluntad de poder, una cambiante constelación de fuerzas que pugnan entre sí para asegurarse la dominación» (4). El poder no es una cosa: el poder 
significa relaciones entre los individuos, de tal manera que uno puede determinar voluntariamente la conducta de otro (5); el poder no está instalado en un órgano central, sino en las relaciones. De igual forma, retomando a Foucault (6), «donde hay poder hay resistencia, y no obstante (o mejor, por lo mismo), ésta nunca está en posición de exterioridad respecto del poder»; es decir, el poder, para ser reconocido y poder ejercerse como tal, necesita una resistencia funcional; por ello, la necesidad imperante de clasificarlo como normal y anormal; sin lo anormal lo normal no es funcional. Por lo tanto, hablar de una nueva normalidad es por sí misma una forma de coartar, dominar y excluir todo aquello que no encaje en esta categorización, y de hacerlo funcional en un sistema.

Hablar de una nueva normalidad, en la pandemia o en la postpandemia, es un ejercicio del biopoder. Forma parte de la misma normalización discursiva para convencer al otro a actuar de cierta manera. De modo que, siguiendo a Foucault (7), «un saber, unas técnicas, unos discursos "científicos" se forman y se entrelazan con la práctica del poder de castigar», sólo que ahora no estamos en la sociedad del castigo, sino en la sociedad del cansancio y en la sociedad autocontrolada por el producir y consumir. Desde el mismo ejercicio de poder, del poder saber, se pretenden naturalizar realidades humanas preexistentes. Una nueva normalidad es algo similar al "discurso del patíbulo"» (7), en el que el condenado a muerte atestiguaba su culpa y la justicia de su sentencia. Ahora, el desempleo, la informalidad laboral, la precariedad de los sistemas de salud, la gran inequidad social, el miedo al otro y la estigmatización forman parte de una «nueva normalidad», en la que parece justificarse todo.

La normalización genera, valga la redundancia, que se normalice el que algunos sujetos queden excluidos de los derechos que se establecen como propios del ser humano. Esa normalización como ejercicio de poder normativo, conduce a hablar del otro, pero no en el sentido esperanzador, sino del otro en sentido discriminato- 
rio, en el que no se acoge la alteridad en un movimiento estático de hospitalidad (8), sino que se dispone del otro; se dispone de la vida desnuda (9), quitando su singularidad y colocándola en el lugar necesario para el funcionamiento normalizado.

Sin embargo, al discurso normativo como ejercicio del biopoder le caben muchos cuestionamientos: ¿qué es y qué no es precisamente lo normal? ¿En qué momento lo normal es funcional para un macro y microsistema de poder? ¿Y cómo se reconfigura lo normal a través de las relaciones, al grado de que es necesario sentir que verdaderamente es una nueva normalidad? De una manera más tangible, esta nueva normalidad condujo a un traslado del panóptico foucaultiano a la vida cotidiana de las personas; es una viva representación del gran hermano de la novela «1984» (10), en la que se vigila y se controla, se mantiene a raya, se utilizan discursos bélicos y eufemismos. Como en la novela, se busca que los excluidos y los necesitados transmitan todo el miedo, odio y sentimientos de su precariedad a un agente externo, en este caso a un virus o a todos aquellos que puedan ser fuente de contagio del virus. Se cree en la libertad, pero se controla desde la libertad y con libertad. En la medida en que se normaliza el mecanismo de control, se puede ser vigilado y controlado, pero se desconoce quién está detrás del dispositivo de control; los castigos y las multas son asumidos netamente como errores de los individuos y no como estrategias del sistema para crear disciplina.

Aunque parezca paradójico, «los países que mejor gestión han tenido durante la pandemia han sido los más autoritarios, los más controladores, en donde, a través de cámaras con sofisticados mecanismos de reconocimiento facial y recopilación de datos, es posible controlar cada movimiento, cada clic, cada relación de las personas» (11). Por eso quedan algunos interrogantes en el aire: jes acaso esto una prueba suficiente para proponer un estado de excepción como la forma más eficiente de gobierno en tiempos de pandemia? ¿Hasta qué punto son necesarias estas medidas de vigilancia y con- 
trol? ¿Cómo se ha instalado de una manera tan dócil un cambio que atraviesa las relaciones humanas y todos los dispositivos de poder?

Ante esta realidad queda en el aire la posibilidad de que dicha normalización de control y vigilancia pueda extenderse más allá de la pandemia, en un estado de excepción eterno (3), pues hemos asistido a un triunfo del «dataísmo», que entiende a cualquier organismo y sociedad como un sistema de procesamiento de datos (12). Los países con mejores sistemas de información, con mejores sistemas de vigilancia y control, obtienen mayor número y mayor calidad de datos sobre los individuos, sobre el proceso salud-enfermedad, la economía y la sociedad en general, lo que les permite gestionar, analizar y tomar decisiones de una manera más rápida y eficaz. Los datos, a su vez, revelan la realidad de los individuos y, a través de los datos, se ejerce poder sobre los individuos. De manera que los discursos apoyados en datos, en medio de una sociedad dataísta, vigilada y controlada, generan un poder abrumador que da certidumbre y tranquiliza, ante el pánico generado por el mismo flujo de datos, la precariedad de los sistemas de salud y una entidad invisible, nueva y sigilosa.

Desde la perspectiva de la ontología, el poder es poder ser. De acuerdo con Heidegger (13), el ser en el mundo es un ser abierto, «es ser desde una posibilidad de sí mismo: de ser sí mismo o de no serlo». Ontológicamente se puede ser o no ser; el poder es esencialmente humano. Como ser finito, el ser humano carece de omnipotencia; es decir, no lo puede todo. Sus posibilidades son finitas, por ende, su poder es limitado y su tiempo también. El poder configura la vulnerabilidad y la limitación como rasgo humano, y un virus trae a la memoria que ni siquiera el poder tecnocientífico lo puede todo. Pero tras el biopoder se pretende anular aquella humanidad vulnerable y configurar una masa burda y poderosa, que normaliza, clasifica y estandariza, incluso a sí misma. Esta masa es la misma sociedad del cansancio de Han (14), una sociedad autómata, presa de sí misma, enferma de tanto trabajar y de tanta tecnología, con necesidades creadas, pero tan comunes que no se reflexiona sobre ellas. 
Este problema es de larga data y ha sido referenciado por otros autores. Séneca (15) afirmaba: «Cuando se trate de la vida feliz, no es propio responder según la cantidad; esta parte parece ser la mayor, pero por eso mismo es la peor. No marchan tan bien los asuntos humanos cuando las cosas mejores agraden a los más; la prueba de lo peor es la muchedumbre». De esta manera, se debe buscar, no lo más acostumbrado, sino lo realmente bueno; para ello se requiere pensar, reflexionar, discutir y proponer, algo difícil en estos días convulsionados, en los que ni siquiera algunos medios de comunicación (16-19) se escapan del biopoder, sino que lo asisten tras bambalinas. Es un tanto similar a lo hecho por Goebbels, sólo que ahora sucede a escala mundial y diversificada, y va desde las redes sociales hasta los periódicos impresos.

De esta forma, en un contexto nietzscheano en medio de la muerte de Dios (20), con la fe puesta en la humanidad, en el sistema capitalista, la tecnociencia y los datos, surgen los discursos normativo-verdaderos que calman la angustia. El biopoder, el poder sobre los cuerpos, se vale de la verdad, de la certeza, para hacer frente a las incertezas y al miedo. A través del saber se ejerce el poder, tomando como premisa que «no hay en el conocimiento una adecuación al objeto, una relación de asimilación, sino que hay, por el contrario, una relación de distancia y dominación. En el conocimiento no hay nada que se parezca a la felicidad o al amor; hay más bien odio y hostilidad; no hay unificación, sino sistema precario de poder» (21). De esta manera se conforma un discurso que conduce a la obediencia. La información, los datos y el conocimiento generan un saber, y éste, a su vez, es una forma de legitimar, justificar y normalizar el poder, para poder crear una «nueva normalidad», que define, decide y normaliza los modos de vida y las relaciones, en una vida sujeta a los designios del poder.

Las limitaciones, la coartación de la libertad de los individuos y otras tantas medidas implementadas para hacerle frente al virus son necesarias (en cierta medida), y a lo mejor insuficientes, puesto 
que dejan de lado a los excluidos, tendiendo a ahondar la brecha con los más favorecidos, excluyendo a más y precarizando las condiciones de los ya excluidos. Sin embargo, aunque algunas medidas sean necesarias, llamar «normal» al pasado, y al presente o futuro inmediato como «nueva normalidad», es un eufemismo cargado de anestesia, que pretende imponer nuevamente el velo de la ignorancia para justificar lo injustificable. Tal vez sea más adecuado hablar de una crisis inusitada con el virus, en medio de una crisis latente, precisamente por dicha latencia. Aquí, el ejercicio biopolítico se hace poco visible desde la comodidad, y se acalla plácidamente a los que están en medio de las incomodidades.

\section{Discusión}

a) Una crisis en medio de otras crisis: una lectura desde la teoría de Jared Diamond

¿Por qué no se le llama «nueva crisis», o simplemente «crisis»? ¿Es acaso la palabra «crisis» una escatología? Si así fuera, con mayor razón debería usarse, pues es la vida humana sobre la tierra lo que está en riesgo. "La palabra "crisis" deriva del sustantivo griego krisis y del verbo krinein, que significa "separar" o "decidir". Crisis es algo que se rompe, y porque se rompe hay que analizarlo [...]. La crisis obliga a pensar, por tanto produce análisis y reflexión» (22). No se le llama crisis, porque se evita a toda costa el análisis y la reflexión. No se quiere aceptar la situación y, por ello, se pretende caer en el juego de normal y anormal, para normalizar lo anormal: desde el cambio climático hasta la inequidad, y desde la recesión económica hasta la lucha a muerte por una vacuna, puesto que, una vez que esté desarrollada, es probable que caiga en la lógica del mercado; es decir, probarla en países pobres con normas laxas, y posteriormente mercantilizarla bajo mecanismos de patentes, al 
amparo del derecho a la propiedad intelectual y convenios internacionales. En momentos de crisis es imperativo llamar a las cosas por su nombre, empezando por la misma crisis, para analizar, reflexionar y buscar decisiones que den un giro, pero no de aquellos de $360^{\circ}$.

De acuerdo con Jared Diamond (23), las crisis individuales son extrapolables en ciertos aspectos a las nacionales, y tal vez también a las mundiales. De manera que se ponen en cuestión la identidad, los valores y la visión del mundo, o al menos eso pasa una vez que se reconoce el problema. De hecho, el primer factor a nivel individual es reconocer que se está en crisis (23), pues es esto lo que permite que las personas busquen ayuda. Podría pensarse que, a nivel global, hablar en términos de pandemia fue el primer paso para reconocer la posibilidad de una crisis y, gracias a ello, se ha logrado la cooperación internacional. No obstante, no se ha concebido estrictamente como crisis y mucho menos se han aceptado las preexistentes, por lo que las medidas instauradas son insuficientes. Aparte del reconocimiento, otros factores que, de acuerdo con Diamond (23), inciden en el desenlace de las crisis nacionales son: «aceptación, construcción del cerco, obtención de ayuda, adopción de otras experiencias como modelo, identidad nacional, autoevaluación honesta, experiencia histórica, asunción de fracasos nacionales, flexibilidad nacional, valores centrales y ausencia de constreñimientos políticos». Como crisis individual, social y global, se propone un análisis tomando como base algunos de los factores anteriormente mencionados.

\section{b) Aceptación de la responsabilidad en la acción}

Fácilmente podría hablarse de responsabilidad nacional y mundial en cuanto a esta crisis en particular, pero poco o nada se ha hablado de la responsabilidad del ser humano en la emergencia sanitaria por el coronavirus que, por cierto, es mucha. Y por responsabili- 
dad no se hace referencia a las teorías conspirativas que proponen intenciones guerreristas para desestabilizar el poder dominante, sino a la responsabilidad desde una perspectiva ecologista $(24,25)$, en la que, fruto de la explotación de la naturaleza sin ningún principio de precaución, se han modificado hábitats, exterminado especies, aumentado la temperatura, ocasionado sequías, y eso sólo por mencionar algunos cambios, cambios que, por cierto, son en gran medida irreversibles y que por ser parte de una situación crítica latente y lenta (aunque cada vez más rápida), no se le ha prestado la atención suficiente, y se sigue llamando cambio climático y no «crisis ecológica», de la cual se ha desprendido una nueva crisis.

Pero la responsabilidad no sólo es a nivel mundial, sino también a nivel de instituciones como la OMS, que se demoró un tanto en nombrar pandemia a una epidemia que se salía de las manos y crecía exponencialmente. También a nivel de naciones, como Brasil, «que nunca reconocieron la gravedad de la epidemia y, por el contrario, se valen de ella para realizar un darwinismo social, eliminando sectores de la población que ya no son de interés para la economía» (26). Y, por supuesto, la responsabilidad se da a nivel individual. Por individual aquí no se incluyen aquellos que no tienen los medios para seguir las recomendaciones y evitar el contagio del virus. La palabra medios es bien amplia en este sentido: comida, agua, jabón, vivienda, información, educación, servicios de salud, entre otros. Pero si se incluyen aquellos que, aun teniendo los medios, no siguieron las indicaciones $\mathrm{y}$, por supuesto, todos aquellos que corrompieron y siguen corrompiendo la política, la salud, educación, vivienda y en general el bienestar de la población, entonces éstos sî que tienen una gran responsabilidad en la presente crisis, las subyacentes y las venideras.

También son responsables aquellos que, teniendo la posibilidad, no tendieron la mano al que la pedía, no ampliaron sus círculos de empatía, sino que, por el contrario, los redujeron. También aquellos que utilizaron la situación para aprovecharse de las necesidades 
ajenas, y aquellos que formaron parte de las cadenas de desinformación, noticias falsas y distribución del miedo. Pero también son responsables otros tantos inocentes, viles peones de un sistema en el que el mal se hace tan banal que se convierte en un mero deber, a través de una discontinuidad entre la motivación de una acción y sus consecuencias (27), al grado de que el mal se cubre en los deberes impuestos para tener cara de bien. En medio de la banalidad del mal y de la normalización de la crisis, todavía hay resistencia, reflexión, ética y solidaridad. Casos como el del patrullero Zúñiga (28), que se rehusó a cumplir las órdenes de desalojar a un grupo de personas y, aunque fue detenido, hoy es considerado un héroe. Esto es un motivo para mantener las esperanzas en que el bien no es banal y que, en medio de la crisis, es posible resistir, pero ante todo responder.

\section{c) Construcción de un cerco para acotar los problemas}

«Implica construir un cerco para delimitar e identificar el problema por resolver, para no verse como un fracaso por completo» (23), y encontrar lo rescatable en medio de la crisis. El problema de este enfoque radica en que, a nivel global-nacional, probablemente sea el factor más pernicioso, pues se carece de la capacidad para establecer límites, con la tendencia a pensar que casi todo, o incluso todo, está bien. Por consiguiente, como todo parece bueno y normal, hay espacio a pocas críticas y, por ende, a poco análisis, lo cual se traduce finalmente en pocos cambios sustanciales que pasan por alto la realidad de los «excluidos», la existencia de crisis subyacentes y la proximidad de las venideras. Usualmente, el cerco de lo bueno es muy amplio: cuanto más grande la crisis, menos selectivo es el cerco y, en vez de incluir más cosas buenas, incluye más cosas malas; lo malo se hace bueno y, con ello, normal; en consecuencia, todo se deja como está, y se hace todo para que lo que es siga siendo y no deje de ser. 


\section{d) Obtención de la ayuda necesaria}

Al contrario del anterior, éste parece el enfoque más esperanzador, pues la actual crisis pone en evidencia que la cooperación, la compasión y la solidaridad son el camino ideal, y que son posibles y necesarios en un mundo en crisis. Es de resaltar la cooperación entre países y la público-privada; la cooperación entre familias e individuos y el acceso abierto al conocimiento de forma inmediata. Sin embargo, un gran interrogante queda sobre la mesa: una vez que esté disponible una vacuna o un tratamiento efectivo, ¿se podrá cooperar con un sistema de patentes ávido de ganancias? Un antecedente un tanto desolador es que:

El control monopólico de la tecnología usada en la detección del virus obstaculizó la pronta introducción de más kits de testeo; igualmente, las 441 patentes de $3 \mathrm{M}$ en las que aparecen las palabras «respirator» o «N95» han puesto trabas a nuevos productores dispuestos a fabricar mascarillas de grado médico a gran escala. Peor aún, tres de los tratamientos utilizados para el Covid 19 (el Remdesivir, el Favipiravir y el Lopinavir/Ritonavir) tenían patentes vigentes en la mayor parte del mundo (29).

Algunos argumentarán que sin ganancias garantizadas no habría paso a investigación y desarrollo de vacunas, lo cual es un desincentivo para el gremio científico. Si bien éste no es el foco de este artículo, quedan dos interrogantes: ¿cuál es el fin de la investigación científica? ¿Qué tendrá más peso: el derecho a la vida o el derecho a la propiedad intelectual?

e) Adopción de las experiencias del otro

Este factor hace referencia al «valor que se le da a los demás como fuente de ayuda; toma como ejemplo a seguir su valor como modelos de métodos de gestión alternativos» (23). Todos los factores van ligados a otros: un caso es la búsqueda de ayuda y la adopción 
de las experiencias del otro, particularmente en esta crisis. Se han tenido modelos a seguir y ello ha facilitado la prevención, la contención y el manejo. Es una forma de ver en el otro un modelo a seguir; es reconocer la finitud propia y al otro como interlocutor válido, lo cual cobra un valor fundamental en el marco ético y en el plano empático-cooperativo. Este es un factor crucial para tener en cuenta y, en adopción a las experiencias del otro, también cabe la no adopción de las experiencias negativas; es decir, adoptar lo bueno y evitar lo malo.

\section{f) Asunción de los fracasos-paciencia}

De acuerdo con lo propuesto por Diamond (23), se refiere a «la capacidad de tolerar la incertidumbre, la ambigüedad de los primeros intentos de solucionar la crisis». Éste podría ser uno de los puntos críticos actuales: ¿se puede pedir paciencia a un macrosistema y geopolítica capitalista? ¿Será posible salvar el yo, dejando de lado la circunstancia? A la primera pregunta, la respuesta es un sí. El sistema dominante, enraizado en el biopoder, se valdrá de sus artimañas para no esperar, para seguir produciendo y «progresando». Pero como lo que mueve el sistema, y con ello a gran parte de la gente, es precisamente la producción y el consumo, se tratará de activar de una manera rápida el sistema, aumentando la producción y el consumo, tras la desaceleración de la economía causada por el virus (30). Sin embargo, no podrá tener cabida en la inmediatez, para hacer resistencia, y no ser el freno para un acelerón letal. Se puede apelar a que la salud prevalece sobre el mercado y, aunque la economía es uno de los determinantes de la salud (31), la salud es considerada grosso modo un bien superior. Ojalá esta misma lógica que prioriza en la jerarquía la salud sobre el mercado pueda aplicarse al desarrollo de la vacuna, y se logre evadir el mercantilismo de patentes. En general, sólo resta esperar. Esperar implica, entre otras cosas, no presionar a la comunidad científica. Si bien es imperiosa una vacuna, no se puede perder el rigor científico, dado 
que «la presión sobre la ciencia (que es lenta porque cumple con aquello de ensayo-error hasta que el error ya no aparece) ha llevado a más desastres que aciertos. La historia reciente es clara en esto» (32). A la segunda pregunta, la respuesta es un no; el yo no es ajeno a la circunstancia; la interdependencia humana es múltiple y ontológica, por lo que el yo siempre es yo y su circunstancia, un yo circunscrito (33).

Estos factores y los faltantes son cruciales en el desarrollo y solución de una crisis, pero la crisis per se genera miedo e incertidumbre. La crisis es «peligro y ocasión» (23), de la misma forma que el miedo por causa de la crisis puede ser peligro y ocasión, en la medida en que puede aturdir y paralizar, o sacudir y movilizar.

\section{g) Del miedo aturdidor a la heurística del miedo}

En un contexto en donde la pelea a muerte con la muerte parecía estar cada vez más cerca de resolverse con un triunfo del lado de la humanidad -incluso con fecha tentativa para el deceso de la muerte hacia 2045 (34)-, ahora un microorganismo, un virus, da una vuelta a esta historia, asestando tal golpe que deja a la humanidad a punto del knockout, y trae a la memoria el recuerdo doloroso de la finitud y la vulnerabilidad humana. En el ambiente previo a la pandemia, parecía que se estaba cada vez más cerca de trascender la humana finitud. Pero bien dice el refrán: «cuanto más alto, más dura será la caída». Por lo tanto, es natural el miedo circundante, «miedo a enfermarse, a contagiar a otros, a morir, a morir solo; a no poder acompañar a los seres queridos, a no poder despedirse; miedo a las penurias, a perder el trabajo; miedo al quebranto existencial» (35).

Sin embargo, es menester que el miedo, al igual que la crisis, no sean dispositivos paralizantes sino, por el contrario, movilizadores. Se necesita una heurística del miedo «en la que la sensación de peligro es una demostración anticipada de la escala planetaria y su calado humano» (36) y, de manera simultánea, conforma una visión 
de la desfiguración del hombre y del ecosistema, que permite alcanzar el concepto de humanidad que ha de ser preservado de tales peligros (36). Resignificar el miedo en tiempos de crisis, para cuidar y movilizar, implica reconocer ante todo la vulnerabilidad intrínseca de todas las formas de vida y de esta casa común con materia viva. $\mathrm{Y}$ esto supone «reconocer al ser humano como sujeto, como sujetado a algo, a la alteridad y a la otredad. Por ello, no sólo debe buscarse el bien humano, sino también el de las cosas extrahumanas, ampliando el reconocimiento de fines en sí mismos más allá de lo humano, e incorporar al concepto de bien humano el cuidado de ellos» (36).

Esta crisis de la crisis no sólo genera miedo, sino también interés. «Sólo hay dos palancas que mueven a los hombres: el miedo y el interés» (37). En este sentido, sólo queda apelar a que el interés sea un interés por lo comunitario, por la vida misma, y no por un egoísmo dañino que agudice la explotación de la alteridad y de la otredad. Y ello para no tener miedo del miedo sino, por el contrario, para reconocerlo en medio de una sociedad que sataniza el reconocerse vulnerable y miedoso ante la incertidumbre de las crisis (38), por lo que se imponen barreras para movilizarse ante los peligros que lo configuran. En medio del miedo, sólo queda reconocer la vulnerabilidad propia, ajena y de la casa común, para responder para, desde y con el otro, por todos, por ellos (los que aún no llegan) y por la vida misma.

\section{b) Del aislamiento social a la compasión y al cuidado del otro}

Un ser social obligado al confinamiento y al distanciamiento social no debería acostumbrarse y normalizar el descuido, el desinterés por el otro sino, por el contrario, fortalecer sus vínculos sociales y las prácticas de cuidado esencialmente compasivas, para dar salida a una crisis sistematizada que orienta al individualismo, en vez de a la cooperación. Es tiempo de recordar para no olvidar y, con ello, reflexionar y actuar. Recordar la finitud, la vulnerabilidad y ese de- 
seo presente (no correspondido) de compañía, como componentes esenciales de la vida humana y de la vida misma; para no dar cabida a una amnesia insensible, que anestesia toda posibilidad de sentir al otro y con el otro.

La compasión proviene del latín cumpassio: cum «convergencia, reunión, junto», y passio, «sentir». A su vez proviene de patior: «padecer, sufrin», más el sufijo -ción «acción y efecto» (39). En sus raíces y orígenes hace referencia a otro, a una relación, a un movimiento, a una respuesta, a una acción que surge en respuesta al sufrimiento del otro; trasciende el ámbito del yo. Siguiendo a Estrada (40), «se trata del reto de hacerse uno con el otro, de traspasar el estrecho horizonte del individualismo y reconocer que todo otro es otrocomo-yo, no una abstracción». Compasión, implica reconocer, entender, estar con y para el otro. Una actitud compasiva y cuidadora es una forma de resistir; de resistir ante la tiranía mercantilista y cosificadora; resistir para subvertir, porque también se requiere una economía solidaria y compasiva que realmente considere al ser humano como fin en sí mismo; que no tome distancias de los sujetos para centrar su atención en la plusvalía, y que tampoco abra más las brechas existentes.

Es preciso recordar, entonces, que «la capacidad de cooperar a gran escala fue lo que catapultó el desarrollo cognitivo del homo sapiens» (41). Es esta misma capacidad de cooperar, pero de una forma extendida y vivificada en la compasión, más allá del «especismo» (42), la que supone un camino de esperanza ante un escenario apocalíptico. Para ampliar los círculos de cooperación, es necesario ampliar los círculos de empatía y compasión. Finalmente, esto se traduciría en una magnificación de los círculos de responsabilidad y cuidado, con los derechos humanos como diámetro de unos círculos de sentimientos y con un centro orientador no antropocéntrico, sino ecocéntrico. Esta crisis y el miedo subyacente suponen un momento para reflexionar en el confinamiento y aislamiento, desde una perspectiva narrativa que permita comprender lo propuesto por Rifkin (43): 
Si la búsqueda de compañía no fuera algo tan básico para nuestra naturaleza no temeríamos el aislamiento o el ostracismo. Ser objeto de rechazo o de destierro es dejar de ser persona, dejar de existir para los demás. La empatía es el medio psicológico por el que pasamos a formar parte de la vida de otras personas y compartimos experiencias valiosas. La noción misma de trascendencia significa ir más allá de uno mismo, ser parte de comunidades más amplias, formar parte de unas redes de significado más complejas (p. 28).

Una comprensión de la vulnerabilidad, de la finitud y temporalidad propia; de la alteridad y de lo otro tiene lugar cuando más individualizado y desarrollado está el yo. Se entiende la individualización no como un ser aislado totalmente independiente, sino indivisible y diferenciado, que no forma parte de la masa burda carente de voluntad propia y de autonomía. Es desde la diferenciación como se comprenden los deseos del otro. En otras palabras, «la autenticidad de lo que he descubierto sobre mí mismo se refuerza porque he visto reafirmado algo de mí en ti y de ti en mí» (44). Es el reconocimiento propio y del otro lo que constituye la identidad propia y de la alteridad, en términos de Honneth (45): «se requiere de la intersubjetividad para constituir la subjetividad. No obstante, no basta con quedarse en la mera constitución en su sentido estricto; implica contribuir también a la constitución del otro a través de su reconocimiento».

Una apertura al cuidado del otro y una expansión de los círculos de cuidado se pueden contemplar desde un mundo cada vez más global, hiperconectado, que es interdependiente incluso en medio del confinamiento, lo cual posibilita la interacción con el extraño. Esto es bien expuesto por Rifkin (46), al comprobar que las poblaciones pequeñas han sido más cerradas y xenófobas. Al ser unas comunidades muy unidas, son mucho más proclives a considerar a los foráneos como extraños, como «otros». Por otro lado, el trato social y comercial cotidiano con personas muy diversas que conlleva la vida urbana suele fomentar una sensibilidad más cosmopolita. Esta crisis global no debe ser una forma para legitimar la coarta- 
ción excesiva de las libertades ni para optar por un canibalismo, en el que el más fuerte hace un festín con el más débil, sino para recordar que cada uno puede hacer algo por el otro cercano. La responsabilidad es, ante todo, responder y, para responder, hay que sentir, pero no basta la responsabilidad en la cercanía; es necesaria en la lejanía espacio-temporal. Para ello, es necesaria una ampliación de los círculos empáticos y compasivos. Siguiendo a Rorty (47), es preciso resignificar la formación en sentimientos, pues ellos no se descubren, sino que se van creando y, en esta tarea, hay que recordar que el arte en todas sus expresiones modela la moral humana, incluso más que un extenso tratado ético-filosófico.

Indudablemente, la crisis deja lecciones; aprenderlas o no es responsabilidad de todos, desde las naciones y organizaciones e instituciones hasta de los sujetos. Hoy más que nunca se necesita de solidaridad, compasión y cuidado, para establecer prioridades entre lo vital y lo superfluo. Pero, ante todo, se requiere resistir a la normalización de lo anormal, a la exclusión de los excluidos, a la vulneración de los derechos y a la anestesia sentimental, moral y ética, ante una crisis actual y otras subyacentes que han sido maquilladas, calladas y abandonadas, pero que hoy aparecen nuevamente escondidas y agudizadas tras el velo de una pandemia.

\section{Referencias bibliográficas}

1. Bratanich A. Mers-Cov: transmisión y el papel de nuevas especies hospederas. Revista Argentina de Microbiología. $1^{\circ}$ de octubre de 2015; 47(4): 279-81. https:// doi.org/10.1016/j.ram.2015.11.001

2. Coronavirus: impacto en la frecuencia de vuelos de las aerolíneas mundiales 2020. Statista. [Consultado el 22 de julio de 2020]. Recuperado en: https:// es.statista.com/estadisticas/1105535/covid-19-impacto-en-la-frecuencia-de-vuelos-de-las-aerolineas-mundiales/ https://doi.org/10.4060/ca8614es

3. Agamben G. La epidemia vista por Agamben y por Giorgio Agamben. Revista Santiago. [Consultado el 22 de julio de 2020]. Recuperado en: http://revista santiago.cl/pensamiento/la-epidemia-vista-por-agamben/ https://doi.org/10.1344/ oxi.2020.i16. 30106 
Covid-19 y biopoder: cómo resistir la normalización de una crisis

4. Nietzsche F. Voluntad de poder. 2a ed. España: EDAF; 2000. [Consultado el 24 de julio de 2020]. Recuperado en: https://ferrusca.files.wordpress.com/2013/08/ voluntad-de-poder.pdf https://doi.org/10.5211/9788496780071.ch9 https://doi.org/ 10.5211/9788496780071.ch9

5. Entrevista con Michel Foucault. Revista de la Asociación Española de Neuropsiquiatría. 2009; 29(1): 137-44. https://doi.org/10.4321/s0211-57352009000100010

6. Foucault M. Historie de la sexualidad. México: Siglo Veintiuno; 2002.

7. Foucault M. Vigilar y castigar: nacimiento de la prisión. Buenos Aires: Siglo Veintiuno; 2004.

8. Torralba Roselló F. Sobre la hospitalidad: extraños y vulnerables como tú. PPC; 2003. 208 p.

9. Agamben G. Homo sacer. Valencia: Pre-Textos; 1998.

10. Orwell G. 1984. España: Debolsillo; 2018.

11. Han B-C. La emergencia viral y el mundo de mañana. Byung-Chul Han, el filósofo surcoreano que piensa desde Berlín. El País. 2020. [Consultado el 24 de julio de 2020]. Recuperado en: https://elpais.com/ideas/2020-03-21/la-emergenciaviral-y-el-mundo-de-manana-byung-chul-han-el-filosofo-surcoreano-que-piensadesde-berlin.html https://doi.org/10.2307/j.ctt1t89k2z.6

12. Harari YN. Homo Deus: Breve historia del mañana. España: Penguin Random House Grupo Editorial España; 2016. 543 p.

13. Heidegger M. Ser y tiempo. 3a ed. Madrid: TROTTA; 2018. 492 p.

14. Byung-Chul H. La Sociedad del cansancio. 2a ed. Herder; 2012. 120 p.

15. Séneca L. De la felicidad. Alianza Editorial; 1980.

16. Médicos en Antioquia rechazaron acusaciones de supuesto "cartel del Covid» Blu Radio. 2020. [Consultado el 12 de octubre de 2020]. Recuperado en: https:// www.bluradio.com/salud/medicos-en-antioquia-rechazaron-acusaciones-de-supuesto-cartel-del-covid https://doi.org/10.17533/udea.iatreia.v28n3a01

17. Acusan a médicos de matar a pacientes en hospital de Ecatepec. Excélsior. 2020. [Consultado el 12 de octubre de 2020]. Disponible en: https://www.excelsior. com. mx/comunidad/acusan-a-medicos-de-matar-a-pacientes-en-hospital-de-ecatepec/1379539 https://doi.org/10.4067/s1726-569x2010000100007

18. Tiempo CEE. «A mí papá no lo mató el Covid-19, sino la mala atención médica». El Tiempo. 2020. [Consultado el 12 de octubre de 2020]. Recuperado en: https:// www.eltiempo.com/colombia/medellin/coronavirus-medellin-un-hombre-hablasobre-la-muerte-de-su-padre-por-covid-524368 https://doi.org/10.1016/j.edumed. 2020.05.005

19. Semana. El escándalo por las unidades de cuidados intensivos. Semana.com Últimas Noticias de Colombia y el Mundo. 2020 [Consultado el 12 de octubre de 2020]. Recuperado en: https://www.semana.com/nacion/articulo/coronavirus-encolombia-escandalo-por-las-uci/677788/ https://doi.org/10.7311/itinerarios.29.2019.11 20. Nietzsche F. Así habló Zaratustra: un libro para todos y para ninguno. Madrid: Alianza; 2003. 504 p.

Medicina y Ética - Enero-Marzo 2021 - Vol. 32 - Núm. 1 


\section{J. C. García Uribe}

21. Arancibia Carrizo JP. El concepto de poder en la obra de Michel Foucault. Santiago de Chile: Universidad de Chile; 2010. https://doi.org/10.5354/0717-8883. 2016.43146

22. CRISIS. Etimologías de Chile. Diccionario que explica el origen de las palabras. [Consultado el 26 de julio de 2020]. Recuperado en: http://etimologias.dechile. net/?crisis https://doi.org/10.36576/summa.29376

23. Diamond J. Crisis: cómo reaccionan los países en momentos decisivos. España: Debate; 2019. 528 p.

24. Bonilla Aldana DK, Dhama K, Rodríguez Morales AJ. Revisiting the one health approach in the context of Covid-19: A look into the ecology of this emerging disease. Adv Anim Vet Sci. 2020. [Consultado el 26 de julio de 2020]; 8(3). Recuperado en: http://nexusacademicpublishers.com/table_contents_detail/4/1359/html https://doi.org/10.17582/journal.aavs/2020/8.3.234.237

25. La crisis del coronavirus, «ejemplo típico de crisis ecológica». RFI. 2020. [Consultado el 26 de julio de 2020]. Recuperado en: https://www.rfi.fr/es/salud/2020 0406-la-crisis-del-coronavirus-ejemplo-típico-de-crisis-ecológica https://doi.org/ 10.22201/crim.001r.2020.13

26. De Sousa B. La cruel pedagogía del virus. Buenos Aires: CLACSO; 2020. 84 p. 27. Arendt H. Eichmann en Jerusalén: un estudio sobre la banalidad del mal. Barcelona: Debolsillo; 2003. https://doi.org/10.3989/arbor.2010.742n1108

28. Revista Semana. Policía no investigará al patrullero Ángel Zúñiga. 2020 [Consultado el 31 de julio de 2020]. Recuperado en: https://www.semana.com/semanatv/semana-noticias/articulo/policia-no-investigara-al-patrullero-angel-zuniga/68 5297 https://doi.org/10.36414/rbmc.v5i12.13

29. Stigliz J, Jayadev A, Prabhala A. ¿Cómo funcionarán las patentes en una eventual vacuna contra el Covid-19? 2020. [Consultado el 30 de abril de 2020]. Recuperado en: https://www.elespectador.com/coronavirus/como-funcionaran-laspatentes-en-una-eventual-vacuna-contra-el-covid-19-articulo-917105 https://doi. org/10.14201/gredos.125903

30. El Covid-19 (coronavirus) hunde a la economía mundial en la peor recesión desde la Segunda Guerra Mundial. World Bank. [Consultado el 27 de julio de 2020]. Recuperado en: https://www.bancomundial.org/es/news/press-release/ 2020/06/08/covid-19-to-plunge-global-economy-into-worst-recession-since-worldwar-ii https://doi.org/10.2307/j.ctv233p84.7

31. Siede JA. Determinates Sociales de la salud y la enfermedad: Sistemas de salud basados en APS. PAHO, editor. 2012; 48.

32. Anjel M. Sobre la nueva vacuna. www.elcolombiano.com. 2020. [Consultado el 27 de julio de 2020]. Recuperado en: https://www.elcolombiano.com/opinion/columnistas/sobre-la-nueva-vacuna-IH13369247

33. Ortega y Gasset J. Meditaciones del Quijote. 70.

34. Cordeiro JL, Wood D. La muerte de la muerte. Vol. 1. Deusto; 2018. 320 p.

35. Cruz J. Carolin Emcke: La pandemia es una tentación autoritaria que invita a la represión. EL PAís. 2020. [Consultado el 30 de julio de 2020]. Recuperado en: 
Covid-19 y biopoder: cómo resistir la normalización de una crisis

https://elpais.com/cultura/2020-04-19/carolin-emcke-esta-es-una-tentacion-autoritaria-que-invita-a-la-represion.html https://doi.org/10.24275/uami.ff3655257

36. Jonas H. El principio de responsabilidad: Ensayo de una ética para la civilización tecnológica. $2^{a}$ edición. Barcelona: Herder; 1995. https://doi.org/10.2307/j.ctv t9k2sz

37. History Channel. Las frases más destacadas de Napoleón. Historia. 2015. [Consultado el 30 de julio de 2020]. Recuperado en: https://canalhistoria.es/blog/ las-frases-mas-destacadas-de-napoleon/ https://doi.org/10.33588/rn.3001.99276

38. Bude H. La sociedad del miedo. Herder; 2017.

39. Corominas J, Pascual JM. Diccionario crítico etimológico castellano e hispánico. CE-F $1^{\mathrm{a}}$ ed., $7^{\mathrm{a}}$ reimpr. Vol. 2. Gredos; 2010.

40. Estrada MRB. Por una ética de la compasión en la educación. Teor. Educ. 2006; 27. https://doi.org/10.14201/3218

41. Harari YN. Sapiens: de animales a dioses. Debate; 2011.

42. Singer P, Casal P. Liberación animal. Madrid: Editorial Trotta; 1999.

43. Rifkin J. La carrera hacia una conciencia global en un mundo en crisis. Barcelona: PPC; 2009. 688 p.

44. Kwok-bun C. Both sides, now: Culture contact, hybridization, and cosmopolitanism. En: Vervotec S, Cohen R, editores. Conceiving cosmopolitanism/: theory, context, and practice. Reino Unido: Oxford University Press; 2002. 204 p.

45. Fraser N, Honneth A. ¿Redistribución o reconocimiento? Un debate políticofilosófico. Madrid: Ediciones Morata; 2006.

46. Rifkin J. La civilización empática: la carrera hacia una conciencia global en un mundo en crisis. España: Paidós; 2010.

47. Rorty R. Contingencia, ironía y solidaridad. España: Paidós; 1991. 224 p. 
